\title{
Patateste (Solanum tuberosum L.) Demir Gübrelemesinin Bitki Gelişimi ve Yumru Verimi Üzerine Etkileri
}

\author{
Merve DEMIR $^{1}$ \\ Sevgi ÇALIŞKAN ${ }^{1}$ \\ ${ }^{1}$ Niğde Ömer Halisdemir Üniversitesi, Ayhan Şahenk Tarım Bilimleri ve Teknolojileri Fakültesi Bitkisel Üretim ve \\ Teknolojileri Bölümü, Merkez, Niğde, 51240, Türkiye \\ $\triangle$ : scaliskan@ohu.edu.tr
}

Geliş (Received): 03.11.2017

Kabul (Accepted): 15.12.2017

\begin{abstract}
ÖZET: Bu çalışma, Türkiye'de yaygın olarak yetiştiriciliği yapılan Agria patates çeşidinde farklı dozlarda uygulanan demir gübrelemesinin bitki gelişimi ile yumru verimi ve kalitesi üzerine etkilerini belirlemek amacıyla, 2016 yılında Niğde Ömer Halisdemir Üniversitesi Tarım Bilimleri ve Teknolojileri Fakültesi Araştırma ve Uygulama Alanında Tesadüf Blokları Deneme Desenine göre üç tekrarlamalı olarak kurulup yürütülmüştür. Denemede 10 farklı demir (Fe) dozu (Fe0: Kontrol (0 Fe g/ha), Fe100: 100 g/ha, Fe100 + 100: $100+100$ g/ha, Fe200: 200 g/ha, Fe150 + 150: $150+150$ g/ha, Fe300: 300 g/ha, Fe200 + 200: $200+200$ g/ha, Fe400: 400 g/ha, Fe250 + 250: $250+250 \mathrm{~g} / \mathrm{ha}$, Fe500: $500 \mathrm{~g} / \mathrm{ha}$ ) uygulaması kullanılmıştır. Demir gübresi uygulaması bitkiler çiçeklenme başlangıcında ve tam çiçeklenme döneminde olmak üzere iki dönemde uygulanmıştır. Denemede EDDHA formunda \%6 oranında Fe içeren demir gübresi kullanılmıştır. Çalışma sonucunda, demir uygulamasının bitki gelişimi, yumru verimi ve yumru kalitesi üzerine önemli etkiye sahip olduğu belirlenmiştir. Araştırmada, en yüksek yumru verimi $3229.0 \mathrm{~kg} / \mathrm{da}$ ile Fe250+250 uygulamasından, en düşük yumru verimi ise $2441.4 \mathrm{~kg} / \mathrm{da}$ ile Kontrol uygulamasından elde edilmiştir. Araştırma sonuçlarına göre, kuvvetli alkali toprak yapısına sahip olan Niğde Bölgesi patates tarım alanlarında demir gübrelemesinin, yumru verim ve kalitesini arttırmak için uygun olacağı sonucuna varılmıştır.
\end{abstract}

Anahtar Kelimeler: Solanum tuberosum, gübreleme, Fe EDDHA, klorofil, yumru verimi

The Effect Of Iron Fertilızation On Plant Growth, Yield And Quality Of Potato (Solanum Tuberosum L.)

ABSTRACT: This study was conducted to determine the effects of iron $(\mathrm{Fe})$ fertilization on plant growth, tuber yield and tuber quality at the field of research and application of Plant Production and Technology Faculty, Nigde Omer Halisdemir University in 2016 year. Agria potato variety which is widely grown in Turkey was used in the study. The experimental design was randomized complete block with three replications. Ten different iron (Fe) dozes (Fe0: Control (0 g Fe ha-1), Fe100: $100 \mathrm{~g}$ Fe ha-1, Fe100 + 100: 100 + $100 \mathrm{~g}$ Fe ha-1, Fe200: $200 \mathrm{~g}$ Fe ha-1, Fe150 + 150: 150 + 150 g Fe ha-1, Fe300: 300 g Fe ha-1, Fe200 + 200: 200 + 200 g Fe ha-1, Fe400: 400 g Fe ha-1, Fe250 + 250: $250+250 \mathrm{~g} \mathrm{Fe}$ ha-1, Fe500: $500 \mathrm{~g}$ Fe ha-1) were applied in the study. The application of Fe fertilizer occurred in 2 times of start of flowering stage and full flowering. Iron which is in the form EDDHA containing $6 \%$ $\mathrm{Fe}$ was used in the experiment. The highest tuber yiels was obtained from the Fe250 + $250(250+250 \mathrm{~g}$ Fe ha-1) application and the lowest tuber yields was obtained from the Fe0: Control $(0 \mathrm{~g} F e \mathrm{ha}-1)$ application $3229.0 \mathrm{~kg} / \mathrm{da}-1$ and $2441.4 \mathrm{~kg} / \mathrm{da}-1$ respectively. Also results showed that the application of iron fertilizer in two times was more effective than one times. It has been concluded that iron fertilization will be suitable for tuber yield and quality in potato production in Nigde region.

Key Words: Solanum tuberosum, fertilization, Fe EDDHA, chlorophyll, tuber yield,

\section{GíRiş}

Patates (Solanum tuberosum L.), geniş kullanım alanı, yüksek verim potansiyeli ve besin değeri nedeniyle büyük tarımsal öneme sahip bitkilerden birisidir. Patates, geniş adaptasyon yeteneğine sahip olup, $70^{\circ}$ kuzey ve $50^{\circ}$ güney enlem dereceleri arasinda yer alan ülkelerde başarıyla yetişebilmektedir. Türkiye, iklim ve toprak özellikleri yönünden patates üretimi için oldukça avantajlı bir konuma sahip olup, ülkenin neredeyse tamaminda ve yılın hemen her döneminde patates üretimi yapılabilmektedir (Çalışkan ve ark., 2010). Patates üretimi genellikle İç Anadolu Bölgesinde yoğunlaşmış olup, Niğde ili patates üretiminde ilk sırada yer almaktadir.

Patateste yumru verimi, başta kullanılan genetik materyal olmak üzere, iklim, toprak koşulları, uygulanan besin elementi miktarı, yetiştirme tekniği gibi birçok faktöre bağlı olarak büyük değişkenlik göstermektedir (Onaran ve Arığlu, 1999). Bu bakımdan, her bir patates çeşidinin yumru oluşturabilmek için ihtiyaç duyduğu ve buna bağlı olarak tüm gelişme dönemleri boyunca topraktan kaldıracağı besin maddesi miktarları birbirinden farklıdır. Patates topraktan yüksek miktarda besin elementi kaldırdığı için yetişme süresi boyunca besin elementi ihtiyacı oldukça yüksektir (Westermann, 2005). Patateste öncelikli olarak üzerinde durulması gerekli besin elementleri makro elementler gibi düşünülse de, mikro besin elementleri (Demir $(\mathrm{Fe})$, Bakır (Cu), Bor (B), Manganez (Mn), Molibden (Mo) ve Çinko $(\mathrm{Zn}))$ patateste verim ve kalite üzerine büyük etkiye sahiptir. Patates bitkisi mikro besin 
elementlerinin düşük seviyelerine çok hassastır ve eksiklik belirtileri kolaylıkla görülmemektedir. Demir $(\mathrm{Fe})$, respirasyon ve fotosentez, klorofil sentezi, azot fiksasyonu (Kim ve Rees, 1992; Chatterjee ve ark., 2005; Gyana ve Sahoo, 2015) ve DNA sentezi (Gyana ve Sahoo, 2015) gibi metebolik olaylarda kritik rol oynadığından bitkiler için temel besin elementlerinden birisidir. Bitkilerde demir eksikliği en yaygın beslenme eksiklikleri arasında yer alır. Demir eksikliği klorozu özellikle alkali kalkerli topraklarda yetiştirilen bitkiler için oldukça yaygın bir problemdir. Patates üretiminin can damarı olan Niğde Bölgesinde topraklar kuvvetli alkali karakterli yapıya sahip olup, yüksek pH içeriğine sahiptir ve böylesi yüksek pH değerine sahip topraklarda yapılan bitki yetiştiriciliğinde demir eksikliği önemli sorunlar yaratmaktadır. $\mathrm{Bu}$ tip topraklarda demir miktarı yeterli düzeyde olsa bile bitki tarafından alınamamakta; özellikle gelişme döneminin başlarında üst genç yapraklar açık yeşil-sarı bir renk almakta, zamanla yapraklar beyaza yakın parlak sarı renge dönüşmekte, klorofil sentezi azalmakta (Chatterjee ve ark., 2006; Wadas ve Diziugiel, 2015) ve buna bağlı olarak ta yumru sayısı ve yumru verimi azalmaktadır (Hadi vd., 2015). Niğde yöresi kireçli topraklara sahip olduğundan tarımsal öneme sahip patates gibi bitkiler sürekli demir eksikliğine maruz kalırlar. Bu noktadan hareketle çalışmamızda farklı dönemlerde ve farklı dozlarda demir gübresi uygulamasının patates bitki büyümesi, verim ve kalite üzerine etkisinin belirlenmesi amaçlanmıştır.

\section{MATERYAL ve YÖNTEM}

Çalışma, 2016 yılı Mayıs ve Ekim ayları arasında Niğde Ömer Halisdemir Üniversitesi Tarım Bilimleri ve Teknolojileri Fakültesi Bitkisel Üretim ve Teknolojileri Bölümü Araştırma ve Uygulama Alanı'nda yürütülmüştür. Deneme alanı toprakları $(0-30 \mathrm{~cm}$ derinlikte), killi-tınlı bünyeye sahip olup, kuvvetli alkali karakterde ( $\mathrm{pH} 8.18)$ ve orta organik madde içeriğine (\%2.05) sahiptir. Denemelerin yürütüldüğü Niğde ili genel özellikleri itibariyle karasal iklim kuşağı içerisinde yer almakta olup, denemelerin yürütüldüğü dönemler içerisinde ortalama sıcaklıklar, $12.4^{\circ} \mathrm{C}$ (Ekim) ile $24.0^{\circ} \mathrm{C}$ (A ğustos); ortalama nispi nem değerleri ise \%63.8 (Mayıs) ile \%40.1 (Temmuz-Ağustos) arasında değişim göstermiştir. Çalışmada yetişme süresi boyunca 133.4 mm yağış gerçekleşmiştir.

Denemede, araştırma materyali olarak Agria (ortageççi) patates çeşidi kullanılmıştır. Bitki şekli uzun, saplar dik-kalın ve orta-az antosiyanlı olup, çiçeklenme fazla ve çiçek rengi beyazdır. Yumrular çok iri, uzunoval, gözler yüzlek, yumru kabuk ve et rengi sarıdır.

Deneme, tesadüf blokları deneme desenine göre üç tekrarlamalı olarak kurulup yürütülmüştür. Deneme alanında ön bitki çavdar olup, ön bitkinin hasadından sonra, toprak 25-30 cm derinliğinde işlenmiştir. Dikim öncesi kültivatör ile ikinci bir toprak işlemesi yapılmış ve arkasından patates dikim makinesi ile dikim yapılacak sırtlar oluşturulmuştur. Dikim öncesi $60 \mathrm{~kg} \mathrm{~N}$ $\mathrm{P}-\mathrm{K} / \mathrm{da}$ oranında $(15+15+15)$ kompoze gübre uygulanmıştır. Denemede tohumluk yumru dikimleri 12 Mayıs tarihinde, 6 metre uzunluğunda 70 x $30 \mathrm{~cm}$ (sıra arası ve sıra üzeri) aralıklı ve her sirada 20 yumru olacak şekilde, 4 sıradan oluşan parsellere $15-18 \mathrm{~cm}$ derinliğe gelecek şekilde el ile yapılmıştır. Denemede 10 farkl 1 demir (Fe) (Fe : Kontrol (0 Fe g/ha), $\mathrm{Fe}_{100}$ : $100 \mathrm{~g} / \mathrm{ha}, \mathrm{Fe}_{100}+100: 100+100 \mathrm{~g} / \mathrm{ha}, \mathrm{Fe}_{200}: 200 \mathrm{~g} / \mathrm{ha}$, $\mathrm{Fe}_{150+150}: 150+150 \mathrm{~g} / \mathrm{ha}, \mathrm{Fe}_{300}: 300 \mathrm{~g} / \mathrm{ha}, \mathrm{Fe}_{200}+200$ : $200+200 \mathrm{~g} / \mathrm{ha}, \mathrm{Fe}_{400}: 400 \mathrm{~g} / \mathrm{ha}, \mathrm{Fe}_{250}+250: 250+250$ $\left.\mathrm{g} / \mathrm{ha}, \mathrm{Fe}_{500}: 500 \mathrm{~g} / \mathrm{ha}\right)$ dozu kullanılmıştır. Çalışmada kullanılan demir, \%6 oranında (EDDHA $\mathrm{Na} F$ formunda) metalik demir içeren suda erir granül formunda olup, demirli gübrenin yarısı çiçeklenme başlangıcı (22 Haziran), diğer yarısı ise tam çiçeklenme döneminde (18 Temmuz) sıraya uygulanarak toprağa karıştırılmış ve arkasından yağmurlama sulama yapılmıştır. Denemenin hasadı, 12 Ekim tarihinde el çapaları kullanılarak yapılmış olup, her parselin kenarında bulunan sıralar ile orta iki sıranın uçlarında bulunan ocaklar kenar tesiri olarak bırakılmıştır.

Çalışmamızda klorofil ölçümleri Minolta SPAD 502 Klorofilmetre yardımıyla yapılmış ve ölçümler demir gübrelemesinden iki gün önce SPAD (1), birinci demir uygulamasindan bir hafta sonra SPAD (2) ve ikinci demir uygulamasından bir hafta sonra SPAD (3) olmak üzere üç dönemde yapılmıştır. Çalışmada, bitki boyu (cm), ocak başına sap sayısı (adet/ocak), pir yaş ve kuru ağırlığı (g/ocak), ocak başına yumru sayısı (adet/ocak) ve yumru verimi (g/ocak), ortalama yumru ağırlığı $(\mathrm{g})$, yumru sinıflaması (\%), kuru madde oranı (\%) ile yumru verimi $(\mathrm{kg} / \mathrm{da})$ gibi özellikler incelenmiştir.

Araştırma sonucunda elde edilen veriler, JMP istatistik paket programı kullanılarak tesadüf blokları deneme desenine göre varyans analizine tabi tutulmuş ve önemlilik gösteren ortalamalar arası farklılıkların karşılaştırılmasında LSD çoklu karşılaştırma testi kullanılmıştır.

\section{BULGULAR ve TARTISMA}

Patates tarımında farklı demir dozu uygulamalarının yaprak klorofil içeriği, pir yaş ve kuru ağırlığı, bitki boyu, ocak başına sap sayısı, ocak başına yumru sayısı, ortalama yumru ağırlığı, I. Sınıf, II. Sınıf ve iskarta yumru oranı, ortalama yumru ağırlığı, kuru madde oranı ve yumru verimi üzerine etkileri açısından elde edilen ortalama değerler Çizelge 1 ve 2'de verilmiştir.

Çalışmamızda farklı demir dozu uygulamaları SPAD 2, SPAD 3, pir yaş ve kuru ağırlığı, ocak başına sap sayısı, ocak başına yumru sayısı, ortalama yumru ağırlığı, I. Sınıf yumru oranı, ıskarta yumru oran1, kuru madde oranı ile yumru verimi üzerine önemli etkide bulunurken; incelenen diğer özellikler açısından demir dozlarının etkisi önemsiz bulunmuştur (Çizelge 1 ve 2). Demir gübrelemesine bağlı olarak yaprak klorofil içeriği değerleri önemli derecede değişmiştir. Demir stres koşullarında patates bitkisinin klorofil konsantrasyonunda azalma görüldüğünü, aynı zamanda stres koşullarında bitki dokularında demir taşınımının engellendiğini (Chatterjee ve ark., 2006) ve demir uygulamasının yaprak klorofil içeriğini arttırdığı yapılan 
çalışmalar ile ortaya konulmuştur (Goas ve Johnson, 2001; Pan ve Wang, 2006; Kobraee ve ark., 2011; Öden, 2012). Pir yaş ve kuru ağırlığı bakımından en düşük değerler Kontrol uygulamasından elde edilmiştir. Chopde ve ark., (2015), uygun konsantrasyonlarda uygulanan demirin, bitkide metabolizmanın enzimatik reaksiyonunda önemli bir katalizör görevi gördüğünü, fotoasimilatların biyosentezine yardımcı olduğunu ve bitkinin vegetatif büyümesini arttırdığını, bunun sonucunda pir yaş ve kuru ağırlığının arttığını bildirmişlerdir (Houimli ve ark., 2015). Patateste, her ne kadar tohumluk yumru üzerinde bulunan gözlerin sürmesi sonucu oluşan ana sapların miktarı üzerine çeşitlerin genetik yapıları yanında tohumluk yumruların büyüklüğü belirleyici etkide bulunsa da (Çalışkan, 1997), kültürel uygulamalardan birisi olan makro besin elementlerinden olan azot (Tunçtürk ve ark., 2004) ve potasyum (Ekin ve ark., 2013) gübrelemesinin patateste ocak başına sap sayısını arttırdığı yapılan çalışmalar ile ortaya konulmuştur.

Çizelge 1. Farklı demir dozu uygulamalarının incelenen özelliklere ait ortalama değerler

\begin{tabular}{|c|c|c|c|c|c|c|c|}
\hline & SPAD 1 & SPAD 2 & SPAD 3 & $\begin{array}{l}\text { Pir Yaş } \\
\text { Ağg. (g) }\end{array}$ & $\begin{array}{l}\text { Pir Kuru } \\
\text { A } \breve{g} .(g)\end{array}$ & $\begin{array}{l}\text { Bitki } \\
\text { Boyu } \\
(\mathrm{cm})\end{array}$ & $\begin{array}{c}\text { Ocak Baş. Sap } \\
\text { Say. } \\
\text { (adet/ocak) }\end{array}$ \\
\hline $\mathrm{Fe}_{0}:$ Kontrol & 47.30 & $52.33 \mathrm{e}$ & $50.10 \mathrm{~d}$ & $112.6 \mathrm{~d}$ & $17.70 \mathrm{~d}$ & 61.87 & $3.47 \mathrm{c}$ \\
\hline $\mathrm{Fe}_{100}$ & 47.37 & $53.13 \mathrm{de}$ & $52.33 \mathrm{c}$ & $113.4 \mathrm{~d}$ & $18.00 \mathrm{~d}$ & 62.20 & $3.60 \mathrm{bc}$ \\
\hline $\mathrm{Fe}_{100+100}$ & 47.17 & $54.17 \mathrm{~cd}$ & $53.00 \mathrm{c}$ & $119.5 \mathrm{~d}$ & $19.04 \mathrm{~d}$ & 62.77 & $3.80 \mathrm{abc}$ \\
\hline $\mathrm{Fe}_{200}$ & 47.03 & $55.07 \mathrm{bc}$ & 53.57 bc & 119. d & $19.25 \mathrm{~d}$ & 62.63 & $4.00 \mathrm{abc}$ \\
\hline Fe $150+150$ & 47.21 & $56.37 \mathrm{ab}$ & $54.60 \mathrm{ab}$ & $130.8 \mathrm{c}$ & $23.04 \mathrm{c}$ & 63.46 & $4.27 \mathrm{abc}$ \\
\hline $\mathrm{Fe}_{300}$ & 47.09 & $56.80 \mathrm{a}$ & $54.80 \mathrm{ab}$ & $136.4 \mathrm{bc}$ & $24.36 \mathrm{bc}$ & 63.40 & $4.43 \mathrm{a}$ \\
\hline $\mathrm{Fe}_{200+200}$ & 47.50 & $57.00 \mathrm{a}$ & $55.77 \mathrm{a}$ & $145.6 \mathrm{ab}$ & $26.89 \mathrm{ab}$ & 63.90 & $4.43 \mathrm{a}$ \\
\hline $\mathrm{Fe}_{400}$ & 47.37 & $57.73 \mathrm{a}$ & $55.90 \mathrm{a}$ & $145.5 \mathrm{sb}$ & $26.57 \mathrm{ab}$ & 63.73 & $3.90 \mathrm{abc}$ \\
\hline $\mathrm{Fe} 250+250$ & 47.46 & $57.17 \mathrm{a}$ & $54.60 \mathrm{ab}$ & $152.1 \mathrm{a}$ & $27.99 \mathrm{a}$ & 64.50 & $4.40 \mathrm{ab}$ \\
\hline Fe500 & 47.33 & $56.73 \mathrm{a}$ & $54.37 \mathrm{~b}$ & $152.8 \mathrm{a}$ & $28.94 \mathrm{a}$ & 64.00 & $3.80 \mathrm{abc}$ \\
\hline LSD (\%5) & 0.63 & 1.51 & 1.33 & 9.44 & 2.92 & 6.17 & 0.83 \\
\hline Tekerrür & 0.401 & 2.149 & 0.908 & 18.334 & 2.598 & 0.366 & 0.949 \\
\hline Uygulama & 0.072öd & $10.018 * *$ & $0.103 * *$ & $750.49 * *$ & $57.510 * *$ & 2.160 öd & $0.380 *$ \\
\hline Hata & 0.135 & 0.770 & 0.605 & 30.290 & 2.906 & 12.952 & 0.231 \\
\hline DK $(\%)$ & 0.78 & 1.58 & 1.30 & 4.14 & 7.36 & 5.69 & 12.00 \\
\hline
\end{tabular}

*,**: Varyans analizinde çeşitler arasındaki farklılık sırasıyla $\% 5$ ve $\% 1$ düzeyinde önemlidir. öd: önemli değil

Birinci sinıf yumru oranı, ortalama tek yumru ağırlığı ile doğrusal bir ilişki içinde olup, (Çalışkan, 1997), bunun sonucunda ortalama tek yumru ağırlığı açısından farklı dönemlerde ve farklı dozlarda uygulanan demir dozları arasında oluşan siralama, birinci sınıf yumru oranı açısından da benzer olmuştur. Çalışmamızda kullandığımız Agria çeşidi, genetik yapısından kaynaklı iri yumru oluşturma özelliği ve güçlü pir geliştirme özelliğine sahip (Çalışkan, 1997) olması nedeniyle, birinci sınıf yumru oranı değerleri yüksek bulunmuştur. Iskarta yumru içerisine çap1 17 mm'den küçük yumrular yanında, yeşillenmiş, çürümüş vb. pazar değeri olmayan yumrular da katıldığı için 1skarta yumru oranı açısından genelde pek tutarlı değerler elde edilememiştir. Yapmış olduğumuz çalışmada ocak başına yumru sayısında dalgalanmalar görülse de genel olarak demir dozu arttıkça ocak başına yumru sayısı değerlerinde azalma olduğu saptanmıştır. Farklı dozlarda uygulanan demir gübresi ortalama yumru ağırlığı üzerine pozitif bir etkiye sahip olmuştur. Demir gübrelemesine bağlı olarak ortalama yumru ağırlığı (g) değerleri önemli derecede değişmiş ve demir gübrelemesine bağlı olarak tek yumru ağırlığı değerleri artmıştır (Jobari ve Hadity, 2014; Hadi ve ark., 2015). Patateste ocak içerisinde sap ve yumru sayısının fazla olması durumunda ocak içi rekabetin artmasına
(Çalışkan, 1997) bağlı olarak ortalama yumru ağırlığı azalma göstermektedir. Nitekim çalışmamızda da en fazla yumru sayısına sahip olan Kontrol uygulaması en düşük tek yumru ağırlığına sahip olmuştur. Farklı dozlarda uygulanan demir gübresi kuru madde oranı üzerine etkili olmuş, demir gübrelemesi ile kuru madde oranı artmıştır fakat yüksek dozlarda uygulanan demir gübresi yumru kuru madde oranını azaltmıştır. Çalışmamızda yüksek demir dozlarında yumruların kuru madde oranlarının azalması, patates bitkisinde yumru oluşumunun başlamasından sonra ana birikim yerinin yumrular olması nedeniyle üretilen kuru maddenin büyük bir kısmının yumrulara gitmesi (Saluzzo ve ark., 1999) yanında, yüksek demir dozlarında pir yaş ağırlığının artmasına bağlı (Çizelge 1) olarak yumruda kuru madde birikiminin azalmasından kaynaklanmış olabilir. Çalışmamızda demir gübresi yumru verimi üzerine etkili olmuş, demir dozlarının artışına paralel olarak yumru verimi artmıştır. En yüksek yumru verimi değeri $\mathrm{Fe}_{250+250}(3229.0 \mathrm{~kg} / \mathrm{da})$ uygulamasından elde edilirken, en düşük değer $2441.4 \mathrm{~kg} / \mathrm{da}$ ile Kontrol $\left(\mathrm{Fe}_{0}\right)$ uygulamasından elde edilmiştir. $\mathrm{Bu}$ sonuçlar, demir gübrelemesinin verime etkisini araştıran bazı araştırmacıların (Pan ve Wang, 2006; Jobori ve Hadithy, 2014; Hadi ve ark., 2015;) sonuçları ile paralellik göstermektedir. 
Çizelge 2. Farklı demir dozu uygulamalarının incelenen özelliklere ait ortalama değerler

\begin{tabular}{|c|c|c|c|c|c|c|c|}
\hline & $\begin{array}{c}\text { I.sinıf } \\
\text { yumru } \\
\text { oranı }(\%)\end{array}$ & $\begin{array}{c}\text { II.sinıf } \\
\text { yumru } \\
\text { oran1 }(\%)\end{array}$ & $\begin{array}{c}\text { Iskarta } \\
\text { yumru } \\
\text { oranı }(\%)\end{array}$ & $\begin{array}{c}\text { Yumru } \\
\text { sayısı } \\
\text { (adet/ocak) }\end{array}$ & $\begin{array}{c}\text { Ort. } \\
\text { Yumru } \\
\text { A ̌̆g. (g) }\end{array}$ & $\begin{array}{c}\text { Kuru } \\
\text { madde } \\
\text { oran1 }(\%)\end{array}$ & $\begin{array}{l}\text { Yumru verimi } \\
(\mathrm{kg} / \mathrm{da})\end{array}$ \\
\hline $\mathrm{Fe}_{0}:$ Kontrol & $96.8 \mathrm{bcd}$ & 1.9 & $1.4 \mathrm{ab}$ & $7.7 \mathrm{a}$ & $66.38 \mathrm{~g}$ & $17.68 \mathrm{e}$ & $2441.4 \mathrm{e}$ \\
\hline $\mathrm{Fe}_{100}$ & $97.2 \mathrm{abcd}$ & 2.1 & $0.7 \mathrm{~cd}$ & $7.3 \mathrm{ab}$ & $72.65 \mathrm{fg}$ & $18.35 \mathrm{bcde}$ & $2502.5 \mathrm{de}$ \\
\hline $\mathrm{Fe}_{100+100}$ & $97.3 \mathrm{abcd}$ & 1.7 & $1.0 \mathrm{bcd}$ & $6.9 \mathrm{bc}$ & $81.69 \mathrm{ef}$ & $19.13 \mathrm{ab}$ & $2663.6 \mathrm{~cd}$ \\
\hline $\mathrm{Fe}_{200}$ & 97.7 abcd & 1.2 & $1.1 \mathrm{bcd}$ & $6.8 \mathrm{bc}$ & $82.52 \mathrm{def}$ & $19.25 \mathrm{a}$ & $266.02 \mathrm{~cd}$ \\
\hline $\mathrm{Fe} 150+150$ & $98.1 \mathrm{abc}$ & 1.0 & $1.0 \mathrm{bcd}$ & $6.4 \mathrm{~cd}$ & $91.23 \mathrm{cde}$ & $18.93 \mathrm{abc}$ & $2805.5 \mathrm{bc}$ \\
\hline $\mathrm{Fe}_{300}$ & $98.3 \mathrm{ab}$ & 1.1 & $0.7 \mathrm{~cd}$ & $6.3 \mathrm{~cd}$ & $92.68 \mathrm{~cd}$ & $18.50 \mathrm{abcd}$ & $2795.8 \mathrm{bc}$ \\
\hline $\mathrm{Fe}_{200+200}$ & $98.4 \mathrm{a}$ & 1.0 & $0.6 \mathrm{~d}$ & $5.9 \mathrm{de}$ & $103.10 \mathrm{~b}$ & 18.37 bcde & $2900.6 \mathrm{~b}$ \\
\hline $\mathrm{Fe}_{400}$ & $98.0 \mathrm{abc}$ & 1.5 & $0.5 \mathrm{~d}$ & $5.9 \mathrm{de}$ & $101.29 \mathrm{bc}$ & 18.37 bcde & $2851.7 \mathrm{bc}$ \\
\hline $\mathrm{Fe} 250+250$ & $96.6 \mathrm{~cd}$ & 2.1 & $1.3 \mathrm{abc}$ & $5.5 \mathrm{e}$ & $122.93 \mathrm{a}$ & $18.30 \mathrm{cde}$ & $3229.0 \mathrm{a}$ \\
\hline Fe500 & $96.3 \mathrm{~d}$ & 1.9 & $1.8 \mathrm{a}$ & $5.9 \mathrm{de}$ & $100.97 \mathrm{bc}$ & $18.08 \mathrm{de}$ & $2822.2 \mathrm{bc}$ \\
\hline LSD (\%5) & 1.55 & 1.17 & 0.65 & 0.69 & 10.24 & 0.81 & 209.59 \\
\hline Tekerrür & 0.508 & 2.116 & 0.125 & 0.130 & 3.124 & 0.019 & 4252.2 \\
\hline Uygulama & $1.622 *$ & $1.288 \mathrm{odd}$ & $0.485^{*}$ & $1.410^{* *}$ & $824.14^{* *}$ & $0.691 *$ & $147298.5 * *$ \\
\hline Hata & 0.814 & 0.469 & 0.144 & 0.162 & 35.657 & 0.223 & 14928 \\
\hline DK $(\%)$ & 0.93 & 44.32 & 37.83 & 6.22 & 6.52 & 2.56 & 4.42 \\
\hline
\end{tabular}

yans analizinde çeșitler arasındaki farklılık sırasıyla $\% 5$ ve $\% 1$ düzeyinde önemlidir

öd: önemli değil

Sonuç olarak, demir gübrelemesinin bitki gelişimi için gerekli olduğu, gübrelemenin tek bir uygulama şeklinde değil iki farklı dönemde uygulanmasının daha etkin olduğu, demir gübrelemesinin tek yumru ağırlığını arttırdığ 1 ve buna bağlı olarak birim alandan elde edilen verimi arttırdığı için gübrelemenin yararlı olacağ 1 sonucuna varılmıştır. Araştırma bulgularına göre $\mathrm{Fe}_{250+250}$ uygulaması patatesin ocak başına yumru verimini, ortalama yumru ağırlığını ve yumru verimini arttırması nedeniyle, Niğde Bölgesi patates yetiştiriciliğinde özellikle pH'sı yüksek topraklarda yapılacak gübre uygulamalarında bu sonucun göz önünde bulundurulması önerilmektedir.

\section{TEŞEKKÜR}

Bu bildiri Niğde Ömer Halisdemir Üniversitesi BAP Koordinatörlügünnce desteklenen FEB 2016/30 numaralı projeden elde edilen verilerden hazırlanmıştır.

\section{KAYNAKLAR}

Chatterjee C, Gopal R ve Dube BK 2006. Impact of iron stress on biomass, yield, metabolis and quality of potato (Solanum tuberosum L.), Scientia Horticulturae 108, 1-6.

Chopde N, Nehare N, Maske SR, Lokhande S ve Bhute PN 2015. Effect of foliar application of zinc and iron on growth, yield and quality of gladiolus, Plant Archives 15, 417-419.

Çalışkan ME 1997. Turfanda patates yetiştiriciliğinde tohumluk yumru iriliği, yumru kesimi ve dikim sıklığının bitki gelişimi, verim ve ürünün ekonomik değeri üzerine etkileri, Doktora Tezi, Çukurova Üniversitesi Fen Bilimleri Enstitüsü, Adana, s.167.

Çalışkan ME, Onaran H, Arıoğlu H 2010. Overview of the Turkish potato sector: Challanges, achievements and expectations, Potato Research, 53: $255-266$.
Hadi MR, Taheri R and Balali GR 2015. Effects of iron and zinc fertilizers on the accumulation of $\mathrm{Fe}$ and $\mathrm{Zn}$ ions in potato tubers. Journal of Plant Nutrition 38, 202-211.

Houimli SIM, Jdidi H, Boujelben F ve Denden M 2015. Improvement of tomato (Lycopersicon esculentum L.) productivity in calcareous soil by iron foliar application, International Journal of Advanced Research 3(9), 1118-1123.

Ekin Z, Demir S, Oğuz F ve Yıldırım B 2013. Farklı potasyum dozlarında arbusküler mikorhizal fungus (AMF) uygulamalarının patates (Solanum tuberosum L.)'in yumru verimi ve yumru iriliği dağ 1 lımı üzerine etkisi, Yüzüncü Yll Üniversitesi Tarım Bilimleri Dergisi. 23(2), 154-163.

Goos RJ and Johnson BE 2001. Seed treatment, seeding rate and cultivar effects on iron deficiency chlorosis of soybean, Journal of Plant Nutrition, 24(8), 12551268.

Gyana RR, Sahoo S 2015. Role of Iron in Plant Growth and Metabolism. Agricultural Science, 3:1-24.

Jobori-AL, K.M.M. and Hadithy-AL, S.A 2014. Response of potato (Solanum tuberosum L.) to foliar application of iron, manganese, copper and zinc, International Journal of Agriculture and Crop Science 7(7), 358-363.

Kim J and Rees DC 1992. Structural models fort he metal centers in the nitrogenase molybdenum-iron protein. Science, 257 (5077): 1677-1682.

Kobraee S, Shamsi K and Ekhtiari S 2011. Soybean nodülation and chlorophyll concentration (SPAD value) affected by some of micronutrients Annals of Biological Research 2(2), 414-422, 2011.

Onaran H ve Arığlu HH, 1999. Determination of suitable plant density for different tuber sizes in table potato growing in the Niğde province", $2^{\text {nd }}$ 
National Potato Congress, Erzurum, Turkey, pp 284 297, 28-30 June.

Öden E 2012. Soya bitkisinde bakteri aşılaması, fosfor ve demir uygulamalarının nodülasyon ve $\mathrm{N}_{2}$ fiksasyonuna etkisi, Yüksek Lisans Tezi, Mustafa Kemal Üniversitesi, Hatay, s. 73.

Pan YL and Wang DW 2016. Effects of iron on potato growth Beijing Academy of Agriculture and Forest Science,

http://www.rd2.co.nz/uploads/Effects\%20of\%20Iron \%20on\%20Potato\%20Growth.pdf, 2016.

Saluzzo JA, Echeverria HE, Andrade FH ve Huarte M 1999. Nitrogen nutrition of potato cultivars differing in maturity, Journal of agronomy and crop science 183(3), 157-165.

Tunçtürk M, Tunçtürk R, Yıldırım B ve Eryiğit T 2004. Değişik azot dozları ve sıra üzeri mesafelerinin patateste (Solanum tuberosum L.) verim ve kalite üzerine etkileri”, Yüzüncü Yıl Üniversitesi Tarım Bilimleri Dergisi 14(2), 95-104.

Wadas W. ve Dziugiel T 2015. Effects of complex fertilizers used in early crop potato culture on loamy sand soil. Journal of Central European Agriculture 16(1), 23-40.

Westermann DT 2005. Nutritional requirements of potatoes, American Journal of Potato Research 82, 301-307. 